\title{
Induction and requirement of gene expression in the anterior cingulate cortex and medial prefrontal cortex for the consolidation of inhibitory avoidance memory
}

Yue Zhang ${ }^{1,2}$, Hotaka Fukushima ${ }^{1,2}$, Satoshi Kida ${ }^{1,2^{*}}$

\begin{abstract}
Background: Memory consolidation is a process to stabilize short-term memory, generating long-term memory. A critical biochemical feature of memory consolidation is a requirement for gene expression. Previous studies have shown that fear memories are consolidated through the activation of gene expression in the amygdala and hippocampus, indicating essential roles of these brain regions in memory formation. However, it is still poorly understood whether gene expression in brain regions other than the amygdala/hippocampus is required for the consolidation of fear memory; however, several brain regions are known to play modulatory roles in fear memory formation.

Results: To further understand the mechanisms underlying the formation of fear memory, we first identified brain regions where gene expression is activated after learning inhibitory avoidance (IA) by analyzing the expression of the immediately early genes c-fos and Arc as markers. Similarly with previous findings, the induction of c-fos and Arc expression was observed in the amygdala and hippocampus. Interestingly, we also observed the induction of c-fos and Arc expression in the medial prefrontal cortex (mPFC: prelimbic (PL) and infralimbic (IL) regions) and Arc expression in the anterior cingulate cortex (ACC). We next examined the roles of these brain regions in the consolidation of IA memory. Consistent with previous findings, inhibiting protein synthesis in the hippocampus blocked the consolidation of IA memory. More importantly, inhibition in the mPFC or ACC also blocked the formation of IA memory.
\end{abstract}

Conclusion: Our observations indicated that the formation of IA memory requires gene expression in the ACC and mPFC as well as in the amygdala and hippocampus, suggesting essential roles of the ACC and mPFC in IA memory formation.

\section{Background}

To form long-term memory (LTM), short-term memory (STM) is stabilized through a process known as memory consolidation [1-3]. A critical biochemical feature of memory consolidation is a requirement for gene expression [3-8].

The expression of immediate-early genes (IEGs), such as c-fos, Arc, and Zif268, is regulated in a neural activity-dependent manner [9-16]. Therefore, the expression

\footnotetext{
* Correspondence: kida@nodai.ac.jp

'Department of Bioscience, Faculty of Applied Bioscience, Tokyo University of Agriculture, Tokyo 156-8502, Japan

Full list of author information is available at the end of the article
}

of IEGs has been used as a marker to identify brain regions that are activated in response to learning or memory retrieval [17-20]. Moreover, the activitydependent expression of IEGs is thought to play a critical role in the formation of LTM [21-25]. Genetic inhibition of transcription factor cAMP-responsive element-binding protein (CREB)-mediated transcription, known as a master regulator of activity-dependent transcription, blocks the consolidation of LTM [26-30]. Consistently, recent genetic studies using mice have shown that the deletion of the Arc or c-fos gene, both of which are targets of CREB, led to the impairment of fear and spatial memories [31,32]. 
In fear conditioning tasks, a conditioned stimulus (CS; such as a context) is paired with an unconditioned stimulus (US; such as footshock). Animals learn this association of CS-US. Abundant studies have shown that the amygdala is a master brain area to learn fear and to form and express fear memories [33-36]. The hippocampus is also another critical area for the formation of several types of fear memory such as contextual fear and inhibitory avoidance (IA) memories [37-46]. Blocking protein synthesis in these brain areas around the time of training blocks the consolidation of fear memory [36,43,44,47-53].

In contrast, it remains poorly understood whether brain areas other than the hippocampus and amygdala play essential roles in the formation or consolidation of fear memory. However, other brain areas have been demonstrated to have critical roles in the regulation or modulation of fear memory. For example, the anterior cingulate cortex (ACC) plays a role in the early formation of contextual fear memory through the activation of the $\mathrm{N}$-methyl-D-aspartate glutamate receptor (NMDAR) NR2B subunit $[54,55]$ and the storage of long-lasting contextual fear memory [18]. On the other hand, the medial prefrontal cortex (mPFC including prelimbic (PL) and infralimbic (IL) regions) modulates the encoding of fear memory via dopamine transmission within the $\mathrm{mPFC}$ [56] and is required for the long-term extinction of fear memory in a gene expression-dependent manner $[20,57,58]$. Interestingly, previous studies have shown that the induction of IEGs or the activation of CREB were observed in the ACC, mPFC (PL and IL regions) [59,60], respectively, after fear conditioning, raising the possibility that these brain areas play essential roles in the formation phases of fear memory in a gene expression-dependent manner.

In this study, to understand the underlying mechanisms for the formation of fear memory, we first investigated brain regions where gene expression was activated after IA learning by analyzing the expression of IEGs. We then examined the roles of gene expression in the identified brain regions in the formation of IA memory.

\section{Results}

\section{Requirement of protein synthesis for the formation} of IA memory

We first tried to confirm the requirement of new gene expression for the formation of IA memory in our experimental conditions (Figure 1). Mice were first placed in the light compartment. Five seconds after mice entered into the dark compartment, a brief electrical footshock was delivered (training). Immediately after training, mice received a systemic injection of anisomycin (ANI; $150 \mathrm{mg} / \mathrm{kg}$ ) or vehicle (VEH). Two or twenty-four hours later, mice were placed back in the light compartment

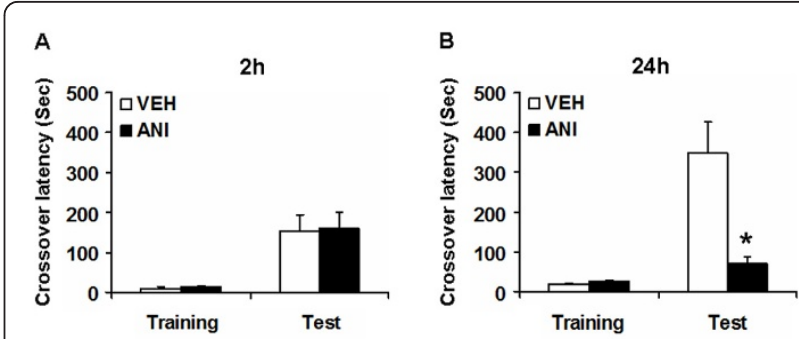

Figure 1 Roles of protein synthesis in ST- and LT-IA memory. (A) Effects of the injection of ANI on STM (VEH group, $n=8$; ANI group, $n=7$ ). (B) Effects of the injection of ANI on LTM (VEH group, $n=8$; ANI group, $n=7$ ). Error bars are SEM. *P $<0.05$ compared with the VEH group.

and we assessed the crossover latency to enter the dark compartment (test). Two-way ANOVA followed by a post hoc Bonferroni's test revealed a significant effect of time (training vs. test), but not drug (VEH vs. ANI), and no significant time vs. drug interaction when $2 \mathrm{~h}$-STM was assessed (time: $\mathrm{F}_{1,26}=25.63, \mathrm{P}<0.05$; drug: $\mathrm{F}_{1,26}=$ $0.029, \mathrm{P}>0.05$; time vs. drug: $\left.\mathrm{F}_{1,26}=0.001, \mathrm{P}>0.05\right)$. Consistently, the post hoc Bonferroni's test revealed that the VEH and ANI groups showed comparable crossover latencies for the $2 \mathrm{~h}-\mathrm{STM}(\mathrm{P}>0.05)$. In contrast, twoway ANOVA identified significant effects of time, drug, and a time vs. drug interaction when $24 \mathrm{~h}$-LTM was assessed (time: $\mathrm{F}_{1,24}=21.780, \mathrm{P}<0.05$; drug: $\mathrm{F}_{1,24}=$ 11.140, $\mathrm{P}<0.05$; time vs. drug: $\left.\mathrm{F}_{1,24}=12.382, \mathrm{P}<0.05\right)$. Consistently, the post hoc Bonferroni's test revealed that the ANI group displayed a significantly shorter crossover latency tested at $24 \mathrm{~h}$ after the training than the $\mathrm{VEH}$ group $(\mathrm{P}<0.05)$. These results indicated that the inhibition of protein synthesis blocked the formation of LTM without affecting STM, and confirmed previous observation that the systemic inhibition of protein synthesis impaired the retention of IA memory [61].

\section{Up-regulation of c-fos expression in distinct brain regions after IA training}

To identify which brain regions were activated when IA memory is generated, we performed immunohistochemistry to measure the expression of the IEG c-fos whose expression is regulated by neuronal activity $[9,15]$. A conditioned group of mice received a footshock after they entered into the dark compartment in the training session (CS-US group). Unconditioned groups were treated similarly, except that they either did not receive a footshock in the dark compartment (CS group), or they directly received a footshock in the dark compartment in the training session without habituating to the light compartment (US group), or they were left undisturbed in their home cages throughout the experiments (home cage group). The unconditioned groups (CS 
and US) showed significantly shorter crossover latencies than the conditioned (CS-US) group during the test at 24 $\mathrm{h}$ after training (Additional file 1). The mice of CS-US, CS, and US groups were assessed c-fos expression at $90 \mathrm{~min}$ after training. The expression levels of $\mathrm{c}$-fos in each brain region for each group were expressed as the ratio of averaged values in the home cage group. We analyzed the expression levels of $\mathrm{c}$-fos in the amygdala [lateral (LA), basolateral (BLA), and central (CeA) regions], hippocampus [CA1, CA3, and dentate gyrus (DG) regions], mPFC [PL and IL regions], ACC, and the other cortical regions [visual cortex (VC), temporal cortex (TC), perirhinal cortex (PRh), and entorhinal cortex (EC) regions].

We first analyzed the expression levels of c-fos in the amygdala. Similarly with a previous finding that c-fos expression in the amygdala was induced after IA training [52], we observed the induction of c-fos expression in the LA and BLA regions, but not in the CeA region of the amygdala in the CS-US group after training in the IA task (Figure 2A, B). One-way ANOVA across the 4 groups (CS-US, CS, US, and home cage) revealed significant effects of group in the LA and BLA regions, but not in the CeA region (Figure 2B; $L A: F_{3,27}=13.762$, $\mathrm{P}<0.05 ; \mathrm{BLA}: \mathrm{F}_{3,27}=9.168, \mathrm{P}<0.05 ; \mathrm{CeA}: \mathrm{F}_{3,27}=$ $0.261, \mathrm{P}>0.05)$. The post hoc Newman-Keuls test showed significantly higher levels of c-fos expression in the LA and BLA regions in the CS-US group than in the other groups (Figure $2 \mathrm{~B}$; $\mathrm{P}<0.05$ ).

We next analyzed the expression levels of $\mathrm{c}$-fos in the hippocampus. Similarly with previous findings that c-fos expression was induced in the hippocampus after IA training $[52,62,63]$, we observed the induction of c-fos expression in the CA1 and CA3 regions, but not in the DG region after training (Figure $2 \mathrm{~A}, \mathrm{C}$ ). One-way ANOVA revealed significant effects of group in the CA1 and $\mathrm{CA} 3$ regions, but not in the $\mathrm{DG}$ region (Figure $2 \mathrm{C}$;

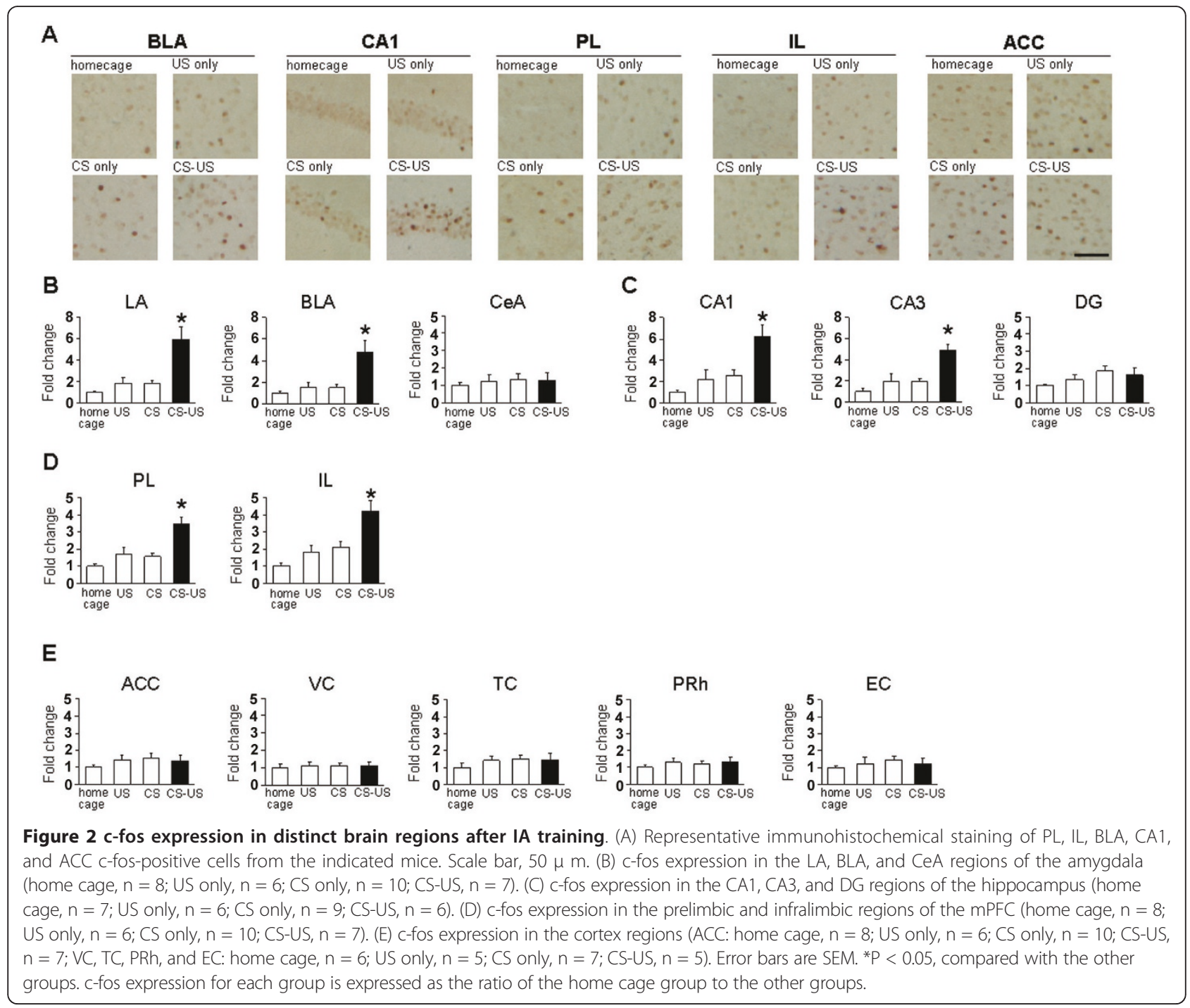


CA1: $\mathrm{F}_{3,24}=8.296, \mathrm{P}<0.05 ;$ CA3: $\mathrm{F}_{3,24}=11.203, \mathrm{P}<$ 0.05 ; DG: $\left.\mathrm{F}_{3,24}=1.547, \mathrm{P}>0.05\right)$. The post hoc Newman-Keuls test showed significantly higher levels of cfos in the CA1 and CA3 regions in the CS-US group than in the other control groups (Figure $2 \mathrm{C}$; $\mathrm{P}<0.05$ )

We next analyzed the expression levels of $\mathrm{c}$-fos in the mPFC. Interestingly, the induction of $\mathrm{c}$-fos expression was observed in the PL and IL regions after training (Figure 2A, D). One-way ANOVA revealed significant effects of group in the PL and IL regions (Figure 2D; PL: $\mathrm{F}_{3,27}=13.417, \mathrm{P}<0.05 ;$ IL: $\left.\mathrm{F}_{3,27}=11.275, \mathrm{P}<0.05\right)$. The post hoc Newman-Keuls test showed significantly higher levels of $\mathrm{c}$-fos in the PL and IL regions in the CS-US group than in the other control groups (Figure $2 \mathrm{D} ; \mathrm{P}<0.05)$. These observations represent the first evidence showing the increased expression of $\mathrm{c}$-fos in the mPFC after training for the IA task.

We finally analyzed the levels of c-fos expression in cortical regions. In contrast to the results described above, there was no increase in the expression of c-fos in the cortical regions analyzed in this study (Figure 2A, E). One-way ANOVA revealed no significant effect of group (Figure 2E; ACC: $\mathrm{F}_{3,27}=0.907, \mathrm{P}>0.05 ; \mathrm{VC}: \mathrm{F}_{3,19}=$ $0.065, \mathrm{P}>0.05 ; \mathrm{TC}: \mathrm{F}_{3,19}=0.524, \mathrm{P}>0.05$; PRh: $\mathrm{F}_{3,19}=$ 0.433, P > 0.05; EC: $\left.\mathrm{F}_{3,19}=0.375, \mathrm{P}>0.05\right)$.

In summary, our anatomical analyses indicated the increased expression of c-fos in the amygdala, hippocampus, and mPFC after learning the IA, raising the possibility that gene expression in these brain regions contributes to the formation of IA memory.

\section{Up-regulation of Arc expression in distinct brain regions after IA training}

To further characterize the brain regions where gene expression was activated following training in the IA task, we next measured the expression of another IEG, Arc, whose expression is regulated by neuronal activity [12-16]. Similarly with the analyses of c-fos expression, 4 groups of mice were analyzed in this experiment. The mice of CS-US, CS, and US groups were assessed Arc expression at $90 \mathrm{~min}$ after training.

Similarly with the results of c-fos expression (Figure 2B-D), IA training induced the expression of Arc in the LA and BLA regions of the amygdala, CA1 and CA3 regions of the hippocampus, and $\mathrm{PL}$ and IL regions of the $\mathrm{mPFC}$, but not in the CeA region of the amygdala or the DG region of the hippocampus in the CS-US group (Figure 3A-D). One-way ANOVA revealed significant effects of group in the LA, BLA, CA1, CA3, $\mathrm{PL}$, and IL regions, but not in the CeA or DG regions (Figure 3B-D; LA: $\mathrm{F}_{3,39}=9.838, \mathrm{P}<0.05$; BLA: $\mathrm{F}_{3,39}=8.659, \mathrm{P}<0.05 ; \mathrm{CA} 1: \mathrm{F}_{3,42}=8.224, \mathrm{P}<0.05 ; \mathrm{CA} 3:$ $\mathrm{F}_{3,42}=5.184, \mathrm{P}<0.05 ; \mathrm{PL}: \mathrm{F}_{3,47}=16.799, \mathrm{P}<0.05 ; \mathrm{IL}:$ $\mathrm{F}_{3,47}=22.213, \mathrm{P}<0.05$; CeA: $\mathrm{F}_{3,39}=1.722, \mathrm{P}>0.05 ; \mathrm{DG}:$
$\left.\mathrm{F}_{3,42}=0.017, \mathrm{P}>0.05\right)$. The post hoc Newman-Keuls test showed significantly higher levels of Arc expression in the LA, BLA, CA1, CA3, PL, and IL regions of the CS-US group than in the other groups (Figure 3B-D; $\mathrm{P}<0.05)$.

More interestingly, in contrast to the results of c-fos expression (Figure 2E), the induction of Arc expression was observed in the ACC region of the CS-US group after training (Figure 3A, E). One-way ANOVA revealed a significant effect of group in the $\mathrm{ACC}$ region $\left(\mathrm{F}_{3,47}=\right.$ 7.035, $\mathrm{P}<0.05)$. The post hoc Newman-Keuls test showed a significantly higher level of Arc expression in the ACC of the CS-US group than in the control groups (Figure 3E; $\mathrm{P}<0.05)$. These observations represent the first evidence showing the increased expression of Arc in the ACC after training in the IA task.

Consistent with the results of c-fos expression, there was no significant induction of Arc expression in the other cortical regions (Figure 3E). One-way ANOVA revealed no significant effect of group in the cortical regions (Figure. 3E; VC: $\mathrm{F}_{3,38}=0.927, \mathrm{P}>0.05$; TC: $\mathrm{F}_{3,38}=0.736, \mathrm{P}>0.05$; PRh: $\mathrm{F}_{3,38}=0.498, \mathrm{P}>0.05 ; \mathrm{EC}:$ $\left.\mathrm{F}_{3,38}=2.500, \mathrm{P}>0.05\right)$.

Taken together with the results of c-fos expression, these results indicated that the expression of IEGs (Arc and c-fos) were induced in the hippocampus, amygdala, and $\mathrm{mPFC}$ after learning the IA, suggesting critical roles for new gene expression in these brain regions in the formation of IA memory. Interestingly, we also observed that IA learning induced the expression of Arc in the $\mathrm{ACC}$, suggesting a potential role of the ACC in the formation of IA memory.

\section{Requirement of protein syntheses in the MPFC and ACC for IA memory formation}

Previous studies have shown that protein synthesis in the hippocampus and amygdala are required for the consolidation of IA memory $[44,47,49,51-53,64]$. Our analyses of gene expression after IA learning raised the possibility that new gene expression in brain regions (mPFC and ACC) other than the hippocampus and amygdala also contributes to the formation of IA memory. To examine this possibility, we tested the effects of inhibiting protein synthesis in the $\mathrm{MPFC}$ or ACC on the formation of IA memory. Mice were trained as described above (Figure 1). Immediately after training, mice received a micro-infusion of ANI $(62.5 \mu \mathrm{g})$ or $\mathrm{VEH}$ into the hippocampus, mPFC, or ACC. Twenty-four hours later, crossover latency (test) was assessed in the mice. Cannula tip placements are shown in the supplementary data (Additional file 2). Only mice with cannula tips within the boundaries of the hippocampus, $\mathrm{mPFC}$, or ACC were included in the data analysis. 


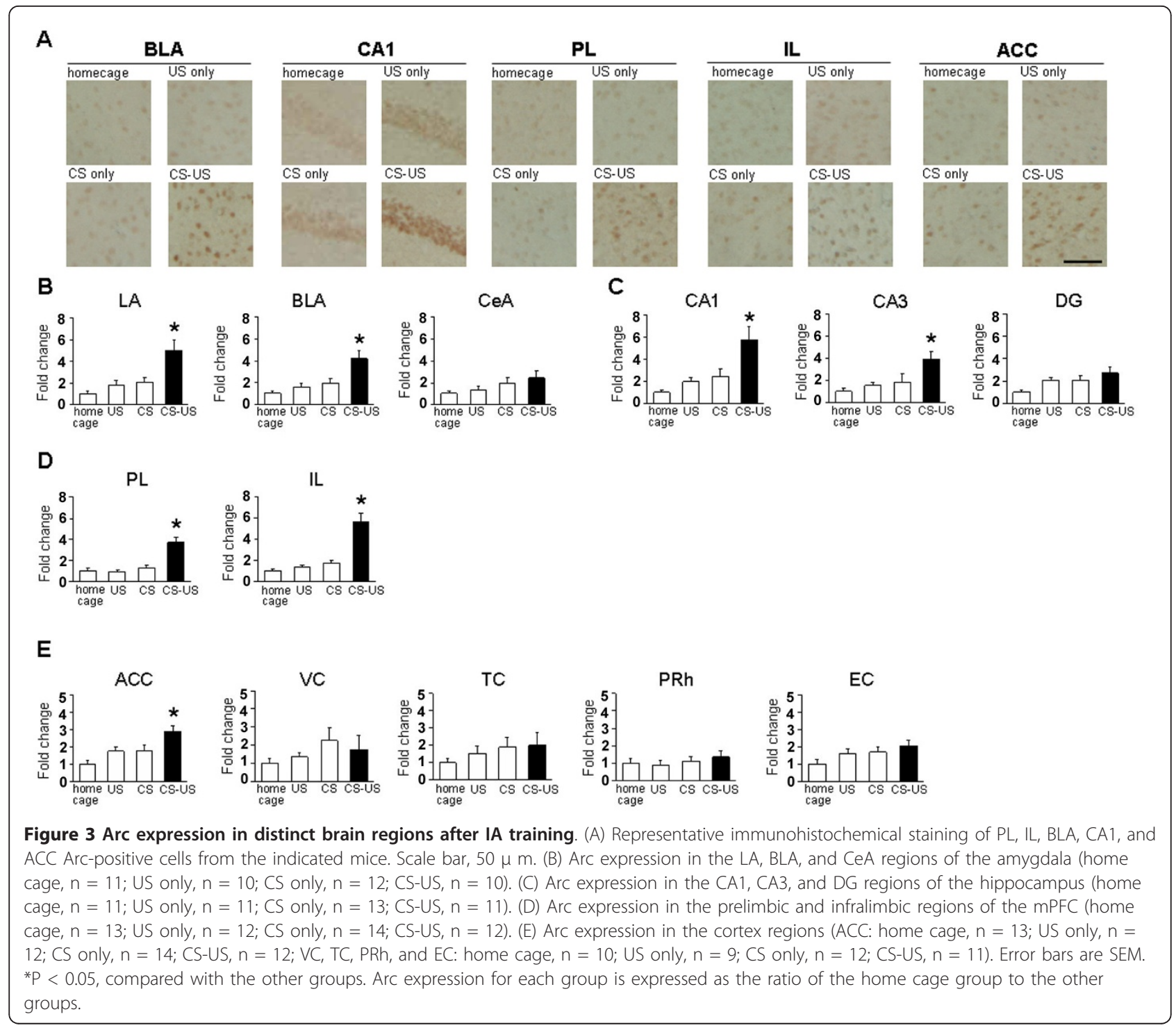

We first tried to confirm previous findings showing the requirement of new protein synthesis in the hippocampus for the formation of IA memory (Figure 4A). Two-way ANOVA identified significant effects of time, drug, and a time vs. drug interaction (time: $F_{1,32}=$ 46.139, $\mathrm{P}<0.05$; drug: $\mathrm{F}_{1,32}=7.735, \mathrm{P}<0.05$; time vs. drug: $\left.\mathrm{F}_{1,32}=7.245, \mathrm{P}<0.05\right)$. The post hoc Bonferroni's test revealed that the ANI group displayed significantly shorter crossover latency at test than the VEH group $(\mathrm{P}<0.05)$. These results indicated that the infusion of ANI into the hippocampus impaired the long-term IA memory and was consistent with previous findings $[44,49,51,64]$, demonstrating that hippocampal protein synthesis is required for the formation of IA memory.

We next examined the effects of inhibiting protein synthesis in the mPFC or ACC (Figure 4B, C).
Interestingly, similar to the results observed in the hippocampus, two-way ANOVA identified significant effects of time, drug, and a time vs. drug interaction (Figure 4B, C; mPFC, time: $\mathrm{F}_{1,28}=66.458, \mathrm{P}<0.05$; drug: $\mathrm{F}_{1,28}=5.130, \mathrm{P}<0.05$; time vs. drug: $\mathrm{F}_{1,28}=5.215, \mathrm{P}<$ 0.05; ACC, time: $\mathrm{F}_{1,40}=47.517, \mathrm{P}<0.05$; drug: $\mathrm{F}_{1,40}=$ 4.761, $\mathrm{P}<0.05$; time vs. drug: $\left.\mathrm{F}_{1,40}=4.222, \mathrm{P}<0.05\right)$. Consistently, the post hoc Bonferroni's test revealed that the ANI groups displayed significantly shorter crossover latencies at test than the VEH groups $(\mathrm{P}<0.05)$. It is important to note that the infusion of ANI into the mPFC or ACC did not affect 2 h-ST-IA memory (Additional file 3 ) and that the inhibition of protein synthesis in the brain regions close to the MPFC or ACC (cannula tips failed to target on boundaries of the MPFC and ACC) did not affect LT-IA memory (Additional file 4). 


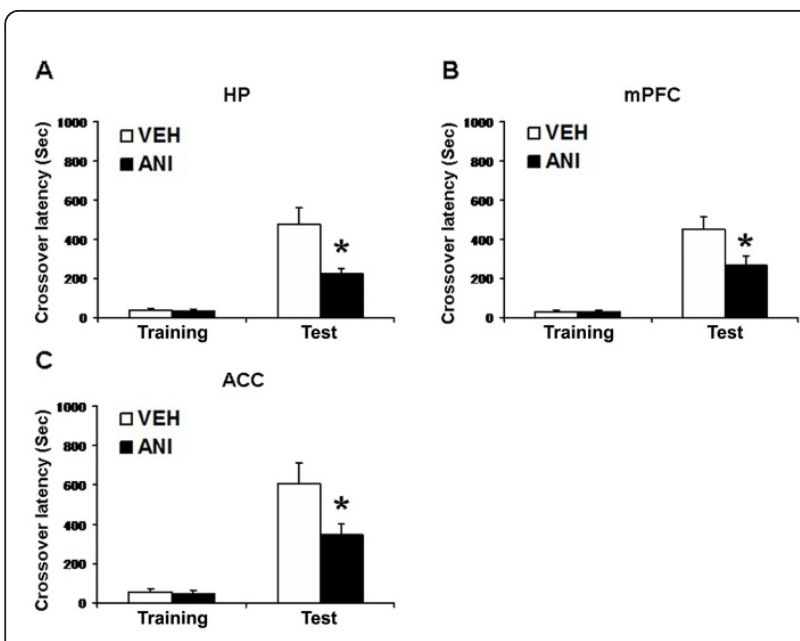

Figure 4 Effects of protein synthesis inhibition in the hippocampus, mPFC, and ACC on the formation of IA memory. (A) Effect of protein synthesis inhibition in the hippocampus ( $n=9$ per group). (B) Effect of protein synthesis inhibition in the mPFC ( $n$ $=8$ per group). (C) Effect of protein synthesis inhibition in the ACC ( $n=11$ per group). Error bars are SEM. ${ }^{*} P<0.05$ compared with the VEH group.

These results indicated that the infusion of ANI into the mPFC or ACC impaired the LT-IA memory without affecting ST-IA memory and that protein synthesis in the $\mathrm{mPFC}$ and $\mathrm{ACC}$ is required for the consolidation of IA memory, suggesting essential roles of the mPFC and ACC in IA memory.

\section{Discussion}

A critical biochemical feature of memory formation is a requirement for gene expression [3-8]. In this study, we investigated brain regions where gene expression is activated after IA learning and the roles of gene expression in these brain regions in the formation of IA memory. To do this, we first showed that IA memory formation depends on new gene expression in our experimental conditions, confirming previous findings [61]. We next analyzed those brain regions where the expression of c-fos and Arc genes was induced because these 2 IEGs are regulated by neuronal activity [9-16] and are targets of CREB, which is required for the consolidation of LTM [26-30]. Importantly, genetic studies have shown that both IEGs are required for the formation of fear memories [31,32].

We observed that the expression of c-fos and Arc was induced in the hippocampus (CA1 and CA3 regions) and amygdala (LA and BLA regions) (Figure $2 \mathrm{~B}, \mathrm{C}$ ). These observations were consistent with previous findings showing that CREB phosphorylation or c-fos expression in the hippocampus and amygdala are induced after IA training $[52,62,63]$. Furthermore, we observed that inhibiting protein synthesis in the hippocampus blocked the formation of LT-IA memory (Figure 4A), confirming previous findings that new gene expression in the hippocampus is required for the formation of LT-IA memory $[44,49,51,64]$. We did not observe the induction of c-fos and Arc expression in the DG region of the hippocampus and the entorhinal cortex following the IA learning, both of which are thought to play a role in encoding and/or storing context component of fear memory [35,65-67]. However, our results did not exclude that possibility that these brain regions play important roles in the formation of IA memory. It is important to examine the expression of other IEGs such as zif268 and the activation of signal transduction pathways including extracellular signal-regulated kinase (ERK) and CaMKII.

More importantly, we observed the induction of c-fos and Arc expression in the PL and IL regions of the mPFC (Figure 2D, 3D) and Arc expression in the ACC after IA training (Figure 3E). Similarly with the observations in the hippocampus, the blockade of protein synthesis in the mPFC or ACC inhibited the formation of LT-IA memory. Taken together with previous findings that inhibition of amygdaloid protein synthesis blocked the formation of LT-IA memory [47,52,53], our observations indicated that the formation of IA memory depends on new gene expression in the mPFC and ACC as well as in the hippocampus and amygdala.

The mPFC has been suggested to play modulatory roles in fear memory. For example, the mPFC modulates the encoding of fear memory via dopamine transmission within the mPFC [56] and the mPFC modulates the consolidation of IA memory by interacting with the basolateral amygdala [68]. In contrast, we showed that gene expression in the $\mathrm{MPFC}$ (PL and IL) is required for the consolidation of IA memory. The previous finding that $\mathrm{c}$-fos expression is induced in the PL and IL regions of mPFC after contextual fear conditioning [59] supports our finding. Furthermore, other studies have shown that spatial, spatial working, object recognition, and long-term extinction memories are consolidated through the activation of gene expression or ERK in the mPFC [69-71]. Therefore, these observations, including ours, suggest that the mPFC plays essential roles in the consolidation of several types of memory.

Previous studies have shown that the ACC is involved in the regulation of fear memory [72-78]. The ACC modulates the consolidation of IA memory by interacting with the basolateral amygdala [79]. More importantly, blocking the activation of the NMDAR NR2B subunit in the ACC impaired contextual fear memory $[54,55]$, indicating direct evidence for an essential role of the ACC in fear memory. Furthermore, the ACC plays a critical role in the storage and/or retrieval of 
remote contextual fear memory [18]. Even though these previous studies did not examine the effects of inhibiting protein synthesis, we showed that protein synthesis inhibition in the ACC blocked the consolidation of IA memory. Our study provides direct evidence indicating that the ACC plays an essential role in the consolidation of fear memory, suggesting that gene expression-dependent long-term neuroplastic changes in the ACC may be required for the formation of fear memory.

In this study, the induction of c-fos expression was observed in the $\mathrm{mPFC}$, but not in the $\mathrm{ACC}$, while the induction of Arc expression was observed in both regions. Nevertheless, protein synthesis inhibition in the mPFC or ACC blocked the formation of IA memory. These observations indicated that the mPFC and ACC display a comparable role in the formation of IA memory, although there are distinct mechanisms by which the expression of Arc and c-fos is induced. Similarly with our findings, previous studies also suggested the distinct regulation of Arc and c-fos expression. For example, experience of a novel taste led to an increase of c-fos mRNA expression in the amygdala and ACC and an increase of Arc mRNA expression in the hippocampus and ACC in mice [13]. Numerous studies have investigated the molecular mechanisms for the transcriptional regulation of the c-fos and Arc genes at the promoter level, and demonstrated the distinct structures of their promoters, regulatory elements, and transcription factors binding to these elements $[16,80,81]$. These different transcriptional regulatory mechanisms may be reflected by the distinct expression of c-fos and Arc genes after IA learning.

Our results suggest that IA memory is encoded in a broad network of cortical/subcortical regions including the mPFC, ACC, hippocampus and amygdala. Previous studies have shown direct connections between the amygdala and mPFC [82-88], amygdala and ACC [89-91], hippocampus and mPFC [92,93] and amygdala and hippocampus $[88,94]$. Especially, the amygdala interacts with many areas of the brain [34,95-97]. Therefore, the interactions among these brain regions may be required for the formation of IA memory. Indeed, previous studies have shown that the hippocampus, ACC and amygdala play critical roles in the formation of fear memory, respectively [75]. In addition, MPFC (PL and IL regions) may be required for some aspect of a decision making by which mice enter into the dark compartment associated with an aversive stimulus from the light compartment. Further studies are required to investigate the roles of these interactions among the hippocampus, amygdala, $\mathrm{mPFC}$, and ACC in the formation of IA memory and to further understand the roles, functions, and molecular signatures of these brain areas in the formation of IA memory.

\section{Methods}

Animals

All experiments were conducted according to the Guide for the Care and Use of Laboratory Animals, Japan Neuroscience Society and the Guide for the Tokyo University of Agriculture. Male C57BL/6 mice were obtained from Charles River (Yokohama, Japan). Five or 6 mice were housed in cages, maintained on a $12 \mathrm{~h}$ light/dark cycle, and allowed ad libitum access to food and water. Mice were at least 8 weeks of age when tested. Testing was performed during the light phase of the cycle. Individual mice were used for all experiments. All experiments were conducted blind to the treatment conditions.

\section{Systemic injections}

ANI (150 mg/kg, i.p.; Wako, Japan) was dissolved in saline ( $\mathrm{pH}$ adjusted to 7.0-7.4 with $\mathrm{NaOH}$ ) and administered to mice immediately after the behavioral manipulation. At this dose, ANI inhibits $>90 \%$ of protein synthesis in the brain during the first $2 \mathrm{~h}$ [98].

\section{Inhibitory avoidance test}

The inhibitory avoidance test was performed as previously described [99]. Step-though inhibitory avoidance apparatus (OHARA Pharmaceutical, Tokyo, Japan) consisted of a box with separate light $(15.5 \times 12.5 \times$ $11.5 \mathrm{~cm})$ and dark $(15.5 \times 12.5 \times 11.5 \mathrm{~cm})$ compartments. The light compartment was illuminated by a fluorescent light (2500 lux). During the training session, each mouse was allowed to habituate to the light compartment for $30 \mathrm{~s}$, and the guillotine door was raised to allow access to the dark compartment. Latency to enter into the dark compartment was considered as a measure of acquisition. Immediately after the mice entered the dark compartment, the guillotine door was closed. After $5 \mathrm{~s}$, a footshock $(0.2 \mathrm{~mA})$ was delivered for a total period of $2 \mathrm{~s}$. Memory was assessed at 2 or $24 \mathrm{~h}$ later as the crossover latency for the mice to enter into the dark compartment when replaced in the light compartment, as in training.

For the first experiment, we examined the effect of protein synthesis inhibition on STM and LTM. Mice received a systemic injection of saline or ANI (150 $\mathrm{mg} / \mathrm{kg}$ ) immediately after training, and memory was assessed at 2 (STM) or 24 (LTM) h later.

For the second experiment (immunohistochemistry), we examined the brain regions where gene expression was activated after training. Mice were divided into 4 groups: 1) CS-US group, mice were trained as described above; 2) CS group, mice received a training session in the absence of a footshock; 3) US group, mice were not allowed to habituate to the light compartment, but directly received a footshock in the dark compartment 
in the training session. The CS-US, CS, and US groups were anesthetized with Nembutal $(750 \mathrm{mg} / \mathrm{kg}$, i.p.) and perfused at 90 min after training. 4) Home cage group; mice were left undisturbed in their home cages throughout the experiment and anesthetized, as above, after they were taken from their home cages.

For the third experiment, we examined the effects of inhibiting protein synthesis in the hippocampus, $\mathrm{MPFC}$, and ACC on IA memory. ANI was dissolved in vehicle solution (artificial cerebrospinal fluid (ACSF)), and adjusted to $\mathrm{pH}$ 7.0-7.4 with $\mathrm{NaOH}$. Mice were trained as described above and received a microinfusion of ANI $(62.5 \mu \mathrm{g})$ or ACSF immediately after training. Two or twenty-four hours after the training session, mice were once again placed in the light box, and crossover latency was assessed.

\section{Immunohistochemistry}

After anesthetization, all mice were perfused with $4 \%$ paraformaldehyde. Brains were then removed, fixed overnight, transferred to $30 \%$ sucrose, and stored at $4^{\circ} \mathrm{C}$. Coronal sections $(30 \mu \mathrm{m})$ were cut in a cryostat. Sections were pretreated with $4 \%$ paraformaldehyde for $20 \mathrm{~min}$ and $3 \% \mathrm{H}_{2} \mathrm{O}_{2}$ in methanol for $1 \mathrm{~h}$, followed by incubation in blocking solution (PBS plus $1 \%$ goat serum albumin, $1 \mathrm{mg} / \mathrm{mL}$ BSA, and $0.05 \%$ Triton $\mathrm{X}-100)$ for $3 \mathrm{~h}$. Consecutive sections were incubated with a polyclonal rabbit primary antibody for anti-c-fos (1:5000; Calbiochem) or anti-Arc (1:1000; Santa Cruz Biotechnology) in the blocking solution overnight. Subsequently, sections were washed with PBS and incubated for $3 \mathrm{~h}$ at room temperature with biotinylated goat antirabbit IgG (SAB-PO kit; Nichirei Biosciences), followed by $1 \mathrm{~h}$ at room temperature in the streptavidin-biotinperoxidase complex (SAB-PO kit). Structures were anatomically defined according to the atlas of Franklin and Paxinos (1997) [100]. Quantification of c-fos- or Arc-positive cells in sections $(100 \times 100 \mu \mathrm{m})$ of the mPFC (bregma between +2.10 and $+1.98 \mathrm{~mm}$ ), ACC (bregma between +0.8 and +1.0 ), amygdala (bregma between -1.22 and $-1.34 \mathrm{~mm}$ ), dorsal hippocampus (bregma between -1.46 and $-1.82 \mathrm{~mm}$ ), VC (bregma between -3.88 and -4.00), TC (bregma between -3.88 and -4.00), PRh (bregma between -3.88 and -4.00), and EC (bregma between -3.88 and -4.00) were analyzed with a computerized image analysis system, as described previously (Winroof version 5.6 software; Mitani Corporation) [20]. Immunoreactive neurons were counted bilaterally with a fixed sample window across at least 3 sections by an experimenter blind to the treatment condition. The expression levels of c-fos and Arc for each group were expressed as the ratio of the averaged values in the home cage control group.

\section{Surgery and microinfusion of drug}

Surgery was performed as described previously $[19,20,101]$. Under Nembutal anesthesia and using standard stereotaxic procedures, stainless steel guide cannulae (22 gauge) were implanted into the $\mathrm{mPFC}(2.7 \mathrm{~mm}, \pm 0$ $\mathrm{mm},-1.6 \mathrm{~mm})$, dorsal hippocampus $(-1.8 \mathrm{~mm}, \pm 1.8 \mathrm{~mm}$, $-1.9 \mathrm{~mm})$, or ACC $(1.0 \mathrm{~mm}, \pm 0 \mathrm{~mm},-1.6 \mathrm{~mm})$. Mice were allowed to recover for at least 1 week after surgery. After this, they were handled for 1 week before the commencement of the IA test. Infusions into the hippocampus, $\mathrm{mPFC}$, or ACC $(0.5 \mu \mathrm{L})$ were made at a rate of $0.25 \mu \mathrm{L} /$ min. This dose of locally infused ANI inhibits $>90 \%$ of protein synthesis for at least $4 \mathrm{~h} \mathrm{[102].}$

\section{Statistics}

Data were analyzed with ANOVA. One-way and post hoc Newman-Keuls comparisons were used to analyze the expression of c-fos and Arc. Two-way ANOVA and post hoc Bonferroni's comparison were used to analyze the effects of time point, drug, and time point vs. drugs interaction. All values in the text and figure legends are means \pm SEM.

\section{Additional material}

Additional file 1: Crossover latencies of CS-US, CS and US groups. CS and US groups showed significantly shorter crossover latencies than CS-US group during the test at $24 \mathrm{~h}$ after training $\left(\mathrm{F}_{3,27}=22.390, \mathrm{P}<\right.$ 0.05). CS-US, $n=11$; CS only, $n=6$; US only, $n=6$. Error bars are SEM. ${ }^{*} \mathrm{P}<0.05$ compared with the unconditioned groups.

Additional file 2: Illustrating cannula tip placements in the hippocampus, mPFC, and ACC. (A-C) Coronal drawing showing the placement of the cannula tip in the hippocampus (A), MPFC (B) and ACC (C). Only mice with needle tips within the boundaries of the hippocampus, mPFC, or ACC were included in the data analysis. VEH, vehicle; ANI, anisomycin.

Additional file 3: Effects of inhibiting protein synthesis in the MPFC and ACC on $\mathbf{2}$ h-STM. (A) Effects of protein synthesis inhibition in the mPFC (VEH group, $n=11$; ANI group, $n=8$ ). (B) Effects of protein synthesis inhibition in the ACC (VEH group, $n=7$; ANI group, $n=9$ ). Two-way ANOVA followed by a post hoc Bonferroni's test revealed a significant effect of time (training vs. test), but not drug (VEH vs. ANI), and no significant time vs. drug interaction when 2 h-STM was assessed (mPFC, time: $F_{1,34}=42.923, P<0.05$; drug: $F_{1,34}=0.888, P>0.05$; time vs. drug: $F_{1,34}=0.907, P>0.05$; ACC, time: $F_{1,28}=45.602, P<0.05$; drug: $F_{1,28}=0.875, P>0.05$; time vs. drug: $\left.F_{1,28}=0.993, P>0.05\right)$. Consistently, the post hoc Bonferroni's test revealed that the VEH and ANI groups showed comparable crossover latencies for the 2 h-ST-IA memory ( $P$ > 0.05). These results indicate that the inhibition of protein synthesis in the MPFC or ACC did not affect ST-IA memory. Error bars are SEM.

Additional file 4: Effects of inhibiting protein synthesis in the brain regions close to the MPFC or ACC. (A) Effects of protein synthesis inhibition in the brain regions where cannula tips failed to target on boundaries of the MPFC and ACC (Non-targeted group). This group showed comparable crossover latencies with VEH group ( $p>0.05 ; \mathrm{VEH}$ group, $n=19$; Non-targeted group, $n=7$ ). (B) Illustrating cannula tip placements of Non-targeted group. These results indicated that the inhibition of protein synthesis in the brain regions close to the MPFC or ACC did not affect LT-IA memory, suggesting that protein synthesis in the MPFC and ACC is specifically required for the formation of LT-IA memory. Error bars are SEM. 


\section{Acknowledgements}

S.K. was supported by Grant-in-Aids for Scientific Research, High Technology Research, and Priority Areas -Molecular Brain Science- (18022038 and 22022039) from the Ministry of Education, Culture, Sports, Science, and Technology, Japan, Core Research for Evolutional Science and Technology, Japan, a Research Grant for Nervous and Mental Disorders from the Ministry of Health, Labor, and Welfare, Japan, The Sumitomo Foundation, Japan and the Takeda Science Foundation, Japan.

\section{Author details}

'Department of Bioscience, Faculty of Applied Bioscience, Tokyo University of Agriculture, Tokyo 156-8502, Japan. ${ }^{2}$ Core Research for Evolutional Science and Technology, Japan Science and Technology Agency, Saitama 332-0012, Japan.

\section{Authors' contributions}

SK is responsible for the hypothesis development and overall design of the research and experiment, and supervised the experimental analyses. SK and YZhang co-wrote the manuscript. YZhang performed biochemical analyses. HF performed systemic injection analyses. YZhang and HF performed behavioral and micro-infusion analyses. All authors read and approved this manuscript.

\section{Competing interests}

The authors declare that they have no competing interests.

Received: 14 December 2010 Accepted: 19 January 2011 Published: 19 January 2011

\section{References}

1. Squire $L R$, Alvarez P: Retrograde amnesia and memory consolidation: a neurobiological perspective. Curr Opin Neurobiol 1995, 5:169-177.

2. Dudai Y: Consolidation, fragility and the road to the engram. Neuron 1996, 17:367-370.

3. McGaugh JL: Memory-a century of consolidation. Science 2000, 287:248-251.

4. Flexner $L B$, Flexner $J B$, Stellar $E:$ Memory and cerebral protein synthesis in mice as affected by graded amounts of puromycin. Exp Neurol 1965, 13:264-272.

5. Davis HP, Squire LR: Protein synthesis and memory. Psychol Bull 1984, 96:518-559.

6. Abel T, Nguyen PV, Barad M, Deuel TA, Kandel ER, Bourtchouladze R: Genetic demonstration of a role for PKA in the late phase of LTP and in hippocampus-based long-term memory. Cell 1997, 88:615-626.

7. Silva AJ, Kogan JH, Frankland PW, Kida S: CREB and memory. Annu Rev Neurosci 1998, 21:127-148.

8. Martin SJ, Grimwood PD, Morris RG: Synaptic plasticity and memory: an evaluation of the hypothesis. Annu Rev Neurosci 2000, 23:649-711.

9. Sheng M, McFadden G, Greenberg ME: Membrane depolarization and calcium induce c-fos transcription via phosphorylation of transcription factor CREB. Neuron 1990, 4:571-582.

10. Abraham WC, Mason SE, Demmer J, Williams JM, Richardson CL, Tate WP, Lawlor PA, Dragunow M: Correlations between immediate early gene induction and the persistence of long-term potentiation. Neuroscience 1993, 56:717-727.

11. Worley PF, Bhat RV, Baraban JM, Erickson CA, McNaughton BL, Barnes CA: Thresholds for synaptic activation of transcription factors in hippocampus: correlation with long-term enhancement. J Neurosci 1993, 13:4776-4786.

12. Guzowski JF, McNaughton BL, Barnes CA, Worley PE: Environment-specific expression of the immediate-early gene Arc in hippocampal neuronal ensembles. Nat Neurosci 1999, 2:1120-1124.

13. Montag-Sallaz M, Welzl H, Kuhl D, Montag D, Schachner M: Noveltyinduced increased expression of immediate-early genes c-fos and arg 3.1 in the mouse brain. J Neurosci 1999, 38:234-246.

14. Guthrie K, Rayhanabad J, Kuhl D, Gall C: Odors regulate Arc expression in neuronal ensembles engaged in odor processing. NeuroReport 2000 11:1809-1813.

15. Kaczmarek L, Robertson HA: Handbook of chemical neuroanatomy. Amsterdam: Elsevier; 2002.

16. Kawashima T, Okuno H, Nonaka M, Adachi-Morishima A, Kyo N, Okamura M, Takemoto-Kimura S, Worley PF, Bito H: Synaptic activity-responsive element in the Arc/Arg3.1 promoter essential for synapse-tonucleus signaling in activated neurons. Proc Natl Acad Sci USA 2008, 106:316-321.

17. Guzowski JF, Setlow B, Wagner EK, McGaugh JL: Experience-Dependent Gene Expression in the Rat Hippocampus after Spatial Learning: A Comparison of the Immediate-Early Genes Arc, c-fos, and zif268. J Neurosci 2001, 21:5089-5098.

18. Frankland PW, Bontempi B, Talton LE, Kaczmarek L, Silva AJ: The involvement of the anterior cingulate cortex in remote contextual fear memory. Science 2004, 304:881-883.

19. Frankland PW, Ding HK, Takahashi E, Suzuki A, Kida S, Silva AJ: Stability of recent and remote contextual fear memory. Learn Mem 2006, 13:451-457.

20. Mamiya N, Fukushima H, Suzuki A, Matsuyama Z, Homma S, Frankland PW, Kida S: Brain Region-Specific Gene Expression Activation Required for Reconsolidation and Extinction of Contextual Fear Memory. J Neurosc 2009, 29:402-413.

21. Robertson HA: Immediate-early genes, neuronal plasticity, and memory. Biochem Cell Biol 1992, 70:729-737.

22. Kaczmarek L: Molecular biology of vertebrate learning: is c-fos a new beginning? J Neurosci Res 1993, 34:377-381.

23. Dragunow M: A role for immediate-early transcription factors in learning and memory. Behav Genet 1996, 26:293-299.

24. Tischmeyer W, Grimm R: Activation of immediate early genes and memory formation. Cell Mol Life Sci 1999, 55:564-574.

25. Inoue N, Nakao H, Migishima R, Hino T, Matsui M, Hayashi F, Nakao K, Manabe T, Aiba A, Inokuchi K: Requirement of the immediate early gene vesl-15/homer-1a for fear memory formation. Mol Brain 2009, 5:2-7.

26. Bourtchuladze R, Frenguelli B, Blendy J, Cioffi D, Schutz G, Silva AJ: Deficient long-term memory in mice with a targeted mutation of the CAMP-responsive element-binding protein. Cell 1994, 79:59-68.

27. Oike Y, Hata A, Mamiya T, Kaname T, Noda Y, Suzuki M, Yasue H, Nabeshima T, Araki K, Yamamura K: Truncated CBP protein leads to classical Rubinstein-Taybi syndrome phenotypes in mice: implications for a dominant-negative mechanism. Hum Mol Genet 1999, 8:387-396.

28. Kida S, Josselyn SA, Ortiz SP, Kogan JH, Chevere I, Masushige S, Silva AJ: CREB required for the stability of new and reactivated fear memories. Nat Neurosci 2002, 5:348-355.

29. Pittenger C, Huang YY, Paletzki RF, Bourtchouladze R, Scanlin H, Vronskaya S, Kandel ER: Reversible inhibition of CREB/ATF transcription factors in region CA1 of the dorsal hippocampus disrupts hippocampusdependent spatial memory. Neuron 2002, 34:447-462.

30. Korzus E, Rosenfeld MG, Mayford M: CBP histone acetyltransferase activity is a critical component of memory consolidation. Neuron 2004, 42:961-972.

31. Fleischmann A, Hvalby O, Jensen V, Strekalova T, Zacher C, Layer LE, Kvello A, Reschke M, Spanagel R, Sprengel R, Wagner EF, Gass P: Impaired long-term memory and NR2A-type NMDA receptor-dependent synaptic plasticity in mice lacking c-Fos in the CNS. J Neurosci 2003, 23:9116-9122.

32. Plath N, Ohana O, Dammermann B, Errington ML, Schmitz D, Gross C, Mao X, Engelsberg A, Mahlke C, Welzl H, Kobalz U, Stawrakakis A, Fernandez E, Waltereit R, Bick-Sander A, Therstappen E, Cooke SF, Blanquet V, Wurst W, Salmen B, Bösl MR, Lipp HP, Grant SG, Bliss TV, Wolfer DP, Kuhl D: Arc/Arg3.1 is essential for the consolidation of synaptic plasticity and memories. Neuron 2006, 52:437-444.

33. Ambrogi-Lorenzini CG, Baldi E, Bucherelli C, Sacchetti B, Tassoni G: Neural topography and chronology of memory consolidation: A review of functional inactivation findings. Neurobiol Learn Mem 1999, 71:1-18.

34. Fanselow MS, LeDoux JE: Why we think plasticity underlying Pavlovian fear conditioning occurs in the basolateral amygdala. Neuron 1999, 23:229-232.

35. LeDoux JE: Emotion circuits in the brain. Annu Rev Neurosci 2000, 23:155-184.

36. Wilensky AE, Schafe GE, Kristensen MP, LeDoux JE: Rethinking the fear circuit: the central nucleus of the amygdala is required for the acquisition, consolidation, and expression of Pavlovian fear conditioning. J Neurosci 2006, 26:12387-12396.

37. Phillips RG, LeDoux JE: Differential contribution of amygdala and hippocampus to cued and contextual fear conditioning. Behav Neurosci 1992, 106:274-285.

38. Kim JJ, Rison R, Fanselow MS: Effects of amygdala, hippocampus and periaqueductal gray lesions on short- and long-term contextual fear. Behav Neurosci 1993, 107:1093-1098. 
39. Myers CE, Gluck MA: Context, conditioning, and hippocampal rerepresentation in animal learning. Behav Neurosci 1994, 108:835-847

40. Lorenzini CA, Baldi E, Bucherelli C, Sacchetti B, Tassoni G: Role of dorsal hippocampus in acquisition, consolidation and retrieval of rat's passive avoidance response: a tetrodotoxin functional inactivation study. Brain Res 1996, 730:32-39.

41. Bernabeu R, Bevilaqua L, Ardenghi P, Bromberg E, Schmitz P, Bianchin M, Izquierdo I, Medina JH: Involvement of hippocampal CAMP/CAMPdependent protein kinase signaling pathways in a late memory consolidation phase of aversively motivated learning in rats. Proc Natl Acad Sci USA 1997, 94:7041-7046.

42. Logue SF, Paylor R, Wehner JM: Hippocampal lesions cause learning deficits in inbred mice in the Morris water maze and conditioned fear task. Behav Neurosci 1997, 111:104-113.

43. Taubenfeld SM, Wiig KA, Bear MF, Alberini CM: A molecular correlate of memory and amnesia in the hippocampus. Nat Neurosci 1999, 2:309-310.

44. Taubenfeld SM, Milekic MH, Monti B, Alberini CM: The consolidation of new but not reactivated memory requires hippocampal C/EBP $\beta$. Nat Neurosci 2001, 4:813-818.

45. Matus-Amat P, Higgins EA, Barrientos RM, Rudy JW: The role of the dorsal hippocampus in the acquisition and retrieval of context memory representations. J Neurosci 2004, 24:2431-2439.

46. Zhang XH, Wu LJ, Gong B, Ren M, Li BM, Zhuo M: Induction- and conditioning-protocol dependent involvement of NR2B-containing NMDA receptors in synaptic potentiation and contextual fear memory in the hippocampal CA1 region of rats. Mol Brain 2008, 1:9.

47. Berman RF, Kesner RP, Partlow LM: Passive avoidance impairment in rats following cycloheximide injection into the amygdala. Brain Res 1978, 158:171-188.

48. Schafe GE, LeDoux JE: Memory consolidation of auditory pavlovian fear conditioning requires protein synthesis and protein kinase $A$ in the amygdala. J Neurosci 2000, 20:RC96.

49. Cammarota M, Bevilaqua LR, Medina JH, Izquierdo I: Retrieval does not induce reconsolidation of inhibitory avoidance memory. Learn Mem 2004, 11:572-578.

50. Huff NC, Rudy JW: The amygdala modulates hippocampus-dependent context memory formation and stores cue-shock associations. Behav Neurosci 2004, 118:53-62

51. Quevedo J, Vianna MR, Martins MR, Barichello T, Medina JH, Roesler R, Izquierdo I: Protein synthesis, PKA, and MAP kinase are differentially involved in short- and long-term memory in rats. Behav Brain Res 2004, 154:339-343.

52. Canal CE, Gold PE: Different temporal profiles of amnesia after intrahippocampus and intra-amygdala infusions of anisomycin. Behav Neurosci 2007, 121:732-741.

53. Milekic $\mathrm{MH}$, Pollonini G, Alberini CM: Temporal requirement of C/EBPbeta in the amygdala following reactivation but not acquisition of inhibitory avoidance. Learn Mem 2007, 14:504-511.

54. Zhao MG, Toyoda H, Lee YS, Wu L, Ko SW, Zhang XH, Jia Y, Shum F, Xu H, Li BM, Kaang BK, Zhuo M: Roles of NMDA NR2B subtype receptor in prefrontal long-term potentiation and contextual fear memory. Neuron 2005, 47:859-872.

55. Zhuo M: Plasticity of NMDA receptor NR2B subunit in memory and chronic pain. Mol Brain 2009, 2:4.

56. Lauzon NM, Bishop SF, Laviolette SR: Dopamine D1 versus D4 receptors differentially modulate the encoding of salient versus nonsalient emotional information in the medial prefrontal cortex. J Neurosci 2009, 29:4836-4845.

57. Santini E, Ge H, Ren K, Peña de Ortiz S, Quirk GJ: Consolidation of fear extinction requires protein synthesis in the medial prefrontal cortex. J Neurosci 2004, 24:5704-5710.

58. Quirk GJ, Gracia R, Gonzalez-Lima F: Prefrontal mechanisms in extinction of conditioned fear. Biol Psychiatry 2006, 60:337-343.

59. Morrow BA, Elsworth JD, Inglis FM, Roth RH: An Antisense Oligonucleotide Reverses the Footshock-Induced Expression of Fos in the Rat Medial Prefrontal Cortex and the Subsequent Expression of Conditioned FearInduced Immobility. J Neurosci 1999, 19:5666-5673.

60. Wei F, Qiu CS, Liauw J, Robinson DA, Ho N, Chatila T, Zhuo M: Calcium calmodulin-dependent protein kinase IV is required for fear memory. Nat Neurosci 2002, 5:573-579.
61. Díaz-Trujillo A, Contreras J, Medina AC, Silveyra-Leon GA, Antaramian A, Quirarte GL, Prado-Alcalá RA: Enhanced inhibitory avoidance learning prevents the long-term memory-impairing effects of cycloheximide, a protein synthesis inhibitor. Neurobiol Learn Mem 2009, 91:310-314.

62. Cammarota $M$, Bevilaqua $L R$, Ardenghi $P$, Paratcha $G$, Levi de Stein $M$, Izquierdo I, Medina JH: Learning-associated activation of nuclear MAPK, CREB and Elk-1, along with Fos production, in the rat hippocampus after a one-trial avoidance learning: abolition by NMDA receptor blockade. Brain Res Mol Brain Res 2000, 76:36-46.

63. Katche C, Bekinschtein P, Slipczuk L, Goldin A, Izquierdo IA, Cammarota M, Medina $\mathrm{JH}$ : Delayed wave of c-Fos expression in the dorsal hippocampus involved specifically in persistence of long-term memory storage. Proc Natl Acad Sci USA 2009, 107:349-354.

64. Bekinschtein P, Cammarota M, Igaz LM, Bevilaqua LRM, Izquierdo I, Medina JH: Persistence of long-term memory storage requires a late protein synthesis-and BDNF-dependent phase in the hippocampus. Neuron 2007, 53:261-277.

65. Fendt M, Fanselow MS: The neuroanatomical and neurochemical basis of conditioned fear. Neurosci Biobehav Rev 1999, 23:743-760.

66. Sanders MJ, Wiltgen BJ, Fanselow MS: The place of hippocampus in fear conditioning. Eur J Pharmacol 2003, 463:217-223.

67. Tinsley MR, Quinn JJ, Fanselow MS: The role of muscarinic and nicotinic cholinergic neurotransmission in aversive conditioning: comparing Pavlovian fear conditioning and inhibitory avoidance. Learn Mem 2004, 11:35-42

68. Roozendaal B, McReynolds JR, Van der Zee EA, Lee S, McGaugh JL, Mclntyre CK: Glucocorticoid effects on memory consolidation depend on functional interactions between the medial prefrontal cortex and basolateral amygdala. J Neurosci 2009, 29:14299-14308.

69. Akirav I, Maroun M: Ventromedial prefrontal cortex is obligatory for consolidation and reconsolidation of object recognition memory. Cereb Cortex 2006, 12:1759-1765.

70. Touzani K, Puthanveettil SV, Kandel ER: Consolidation of learning strategies during spatial working memory task requires protein synthesis in the prefrontal cortex. Proc Natl Acad Sci USA 2007, 104:5632-5637.

71. Leon WC, Bruno MA, Allard S, Nader K, Cuello AC: Engagement of the PFC in consolidation and recall of recent spatial memory. Learn Mem 2010, 17:297-305.

72. Gabriel M, Kubota Y, Sparenborg S, Straube K, Vogt BA: Effects of cingulated cortical lesions on avoidance learning and training-induced unit activity in rabbits. Exp Brain Res 1991, 86:585-600.

73. Riekkinen P Jr, Kuitunen J, Riekkinen M: Effects of scopolamine infusions into the anterior and posterior cingulate on passive avoidance and water maze navigation. Brain Res 1995, 685:46-54

74. Tang J, Ko S, Ding HK, Qiu CS, Calejesan AA, Zhuo M: Pavlovian fear memory induced by activation in the anterior cingulate cortex. Mol Pain 2005, 1:6.

75. Malin EL, McGugh JL: Differential involvement of the hippocampus, anterior cingulate cortex, and basolateral amygdala in memory for context and footshock. Proc Natl Acad Sci USA 2006, 103:1959-1963.

76. Liu F, Zheng XL, Li BM: The anterior cingulate cortex is involved in retrieval of long-term/long-lasting but not short-term memory for stepthrough inhibitory avoidance in rats. Neurosci Lett 2009, 460:175-179.

77. Steenland HW, Wu V, Fukushima H, Kida S, Zhuo M: CaMKIV overexpression boosts cortical 4-7 $\mathrm{Hz}$ oscillations during learning and 1-4 Hz delta oscillations during sleep. Mol Brain 2010, 3:16.

78. Chai SC, Kung JC, Shyu BC: Roles of the anterior cingulate cortex and medial thalamus in short-term and long-term aversive information processing. Mol Pain 2010, 6:42.

79. Malin EL, Ibrahim DY, Tu JW, McGaugh JL: Involvement of the Rostral Anterior Cingulate Cortex in Consolidation of Inhibitory Avoidance Memory: Interaction with the Basolateral Amygdala. Neurobiol Learn Mem 2007, 87:295-302.

80. Robertson LM, Kerppola TK, Vendrell M, Luk D, Smeyne RJ, Bocchiaro C, Morgan Jl, Curran T: Regulation of c-fos expression in transgenic mice requires multiple interdependent transcription control elements. Neuron 1995, 14:241-252.

81. Waltereit R, Dammermann B, Wulff P, Scafidi J, Staubli U, Kauselmann G, Bundman M, Kuhl D: Arg3.1/Arc mRNA induction by Ca2+ and CAMP requires protein kinase $A$ and mitogen-activated protein kinase/ extracellular regulated kinase activation. J Neurosci 2001, 21:5484-5493.

82. McDonald AJ: Organization of amygdaloid projections to the prefrontal cortex and associated striatum in the rat. Neuroscience 1991, 44:1-14. 
83. Pérez-Jaranay JM, Vives F: Electrophysiological study of the response of medial prefrontal cortex neurons to stimulation of the basolateral nucleus of the amygdala in the rat. Brain Res 1991, 564:97-101.

84. Rosenkranz JA, Grace AA: Cellular mechanisms of infralimbic and prelimbic prefrontal cortical inhibition and dopaminergic modulation of basolateral amygdala neurons in vivo. J Neurosci 2002, 22:324-337.

85. Rosenkranz JA, Moore H, Grace AA: The prefrontal cortex regulates lateral amygdale neuronal plasticity and responses to previously conditioned stimuli. J Neurosci 2003, 23:11054-11064.

86. Maroun M, Richter-Levin G: Exposure to acute stress blocks the induction of long-term potentiation of the amygdala-prefrontal cortex pathway in vivo. J Neurosci 2003, 1:4406-4409.

87. Likhtik E, Pelletier JG, Paz R, Paré D: Prefrontal control of the amygdala. J Neurosci 2005, 25:7429-7437.

88. Herry C, Ciocchi S, Senn V, Demmou L, Müller C, Lüthi A: Switching on and off fear by distinct neuronal circuits. Nature 2008, 454:600-606.

89. Krettek JE, Price JL: Projections from the amygdaloid complex to the cerebral cortex and thalamus in the rat and cat. J Comp Neurol 1977, 172:687-722.

90. Sarter M, Markowitsch HJ: Convergence of basolateral amygdaloid and mediodorsal thalamic projections in different areas of the frontal cortex in the rat. Brain Res Bull 1983, 10:607-622.

91. Sripanidkulchai K, Sripanidkulchai B, Wyss JM: The cortical projection of the basolateral amygdaloid nucleus in the rat: a retrograde fluorescent dye study. J Comp Neurol 1984, 229:419-431.

92. Jay TM, Burette F, Laroche S: NMDA receptor-dependent longterm potentiation in the hippocampal afferent fiber system to the prefrontal cortex in the rat. Eur J Neurosci 1995, 7:247-250.

93. Takita M, Izaki Y, Jay TM, Kaneko H, Suzuki SS: Induction of stable longterm depression in vivo in the hippocampal-prefrontal cortex pathway. Eur J Neurosci 1999, 11:4145-4148.

94. Pitkänen A, Pikkarainen $M$, Nurminen N, Ylinen A: Reciprocal connections between the amygdala and the hippocampal formation, perirhinal cortex, and postrhinal cortex in rat. A review. Ann N Y Acad Sci 2000, 911:369-391.

95. Packard MG, Cahill L, McGaugh JL: Amygdala modulation of hippocampaldependent and caudate nucleus-dependent memory processes. In Proc Natl Acad Sci. Volume 91. USA; 1994:8477-8481.

96. Garcia R, Vouimba RM, Baudry M, Thompson RF: The amygdala modulates prefrontal cortex activity relative to conditioned fear. Nature 1999, 402:294-296.

97. McGaugh JL: The amygdala modulates the consolidation of memories of emotionally arousing experiences. Annu Rev Neurosci 2004, 27:1-28.

98. Flood JF, Rosenzweig MR, Bennett EL, Orme AE: The influence of duration of protein synthesis inhibition on memory. Physiol Behav 1973, 10:555-562.

99. Fukushima H, Maeda R, Suzuki R, Suzuki A, Nomoto M, Toyoda H, Wu L, Xu H, Zhao MG, Ueda K, Kitamoto A, Mamiya N, Yoshida T, Homma S, Masushige S, Zhuo M, Kida S: Upregulation of Calcium/CalmodulinDependent Protein Kinase IV Improves Memory Formation and Rescues Memory Loss with Aging. J Neurosci 2008, 28:9910-9919.

100. Franklin KB, Paxinos G: The mouse brain in stereotaxic coordinates. San Diego: Elesevier Academic; 1997.

101. Suzuki A, Mukawa T, Tsukagoshi A, Frankland PW, Kida S: Activation of LVGCCS and CB1 receptors required for destabilization of reactivated contextual fear memories. Learn Mem 2008, 15:426-433.

102. Rosenblum K, Meiri N, Dudai Y: Taste memory: the role of protein synthesis in gustatory cortex. Behav Neural Biol 1993, 59:49-56.

doi:10.1186/1756-6606-4-4

Cite this article as: Zhang et al.: Induction and requirement of gene expression in the anterior cingulate cortex and medial prefrontal cortex for the consolidation of inhibitory avoidance memory. Molecular Brain $20114: 4$ 